\title{
Dissection of mucosa and muscularis mucosa instead of submucosal dissection: rapid retroflow of the injection fluid can be an indicator
}

Peroral endoscopic myotomy (POEM) in sigmoid achalasia is a cumbersome technique even in trained hands. "Difficult POEM" is a new terminology associated with complex achalasia [1-3]. Several complications can occur during difficult POEM, including inability to make a tunnel incision due to submucosal fibrosis, disorientation, mucosal perforation, or detachment of clips, which is associated with mucosal infection on the edges of the tunnel.

We performed difficult POEM in a 65year-old man with type 1 achalasia (sigmoid type 2). Prolonged contact of the esophageal mucosa with food in sigmoid achalasia causes mucosal edema and ulcerations that lead to submucosal fibro- sis. Unhealthy mucosa causes delayed closure of the tunnel edges. In our patient, small ulcers were present, and disappearance of the submucosal vasculature was a consequence of mucosal edema. The mucosa rapidly swelled as we began the submucosal injection. After withdrawing the injection needle, the injected solution immediately flowed back into the lumen. The mucosal incision was completed with a triangle knife; however, the area reached following the incision was not the submucosa but the space between the mucosa and the muscularis mucosa. The submucosal space was found with the triangle knife and a tunnel opening was created (> Fig.1). As we did not see expansion of the mu- cosa following the submucosal injection, we determined that injection was into the muscular layer. These findings should be interpreted as misplacement of the injection. Rapid mucosal swelling during injection and rapid discharge of the solution following needle withdrawal should be a warning that the needle might be between the mucosa and the muscularis mucosa and not the submucosa ( $\downarrow$ Video 1 ).

To our knowledge, this is the first report of tunnel opening during POEM in a patient with sigmoid achalasia and describes a solution to a technical issue.

Endoscopy_UCTN_Code_CPL_1AH_2A
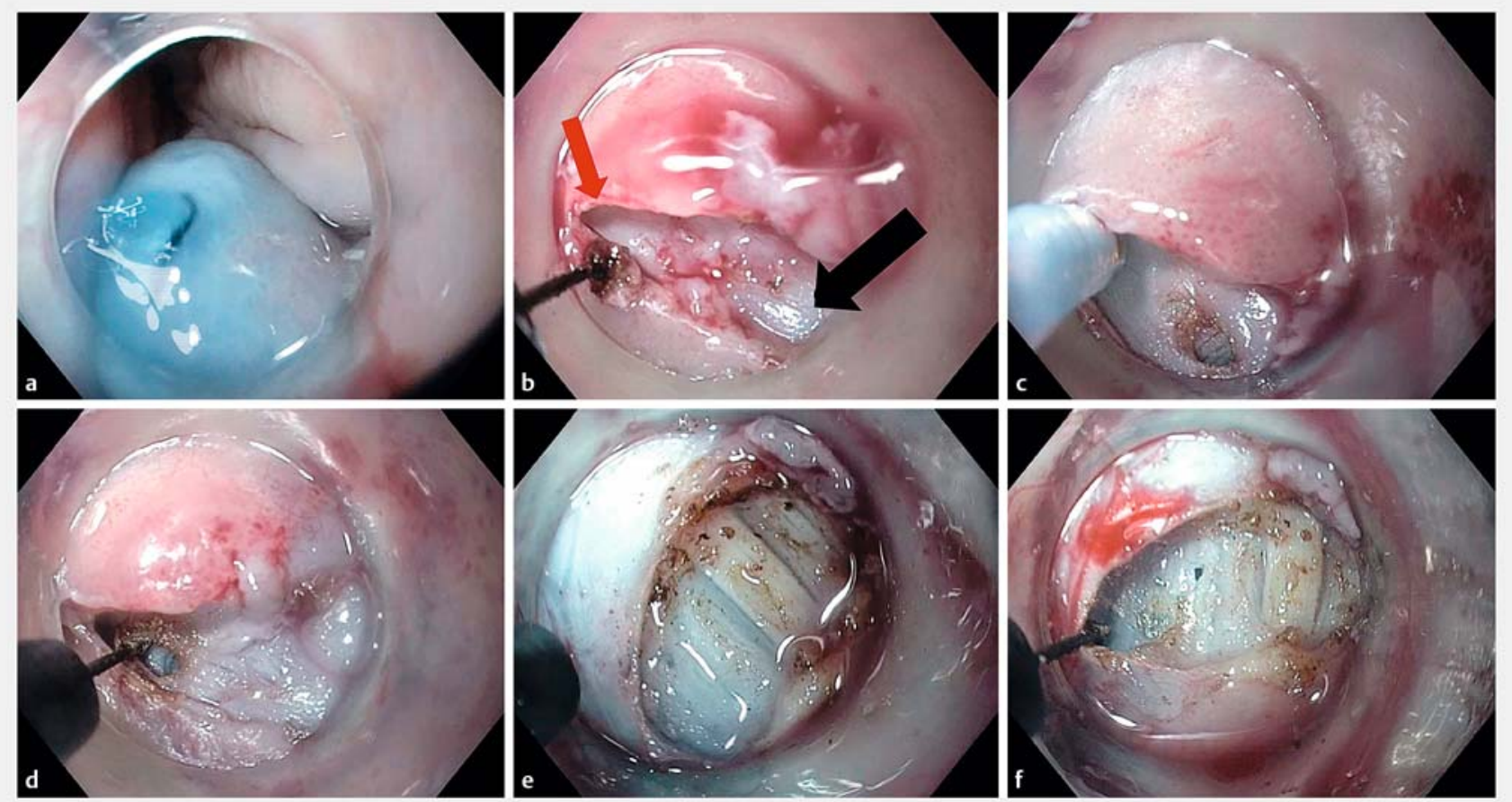

Fig. 1 Endoscopic images. a Rapid retroflow of the injection fluid. $\mathbf{b}$ The red arrow points to the mucosa and the black arrow points to the muscularis mucosa. The submucosal area is below the area indicated by the black arrow (muscularis mucosa). c After locating the submucosa under the muscularis mucosa, the submucosal injection was repeated. d,e After the submucosal area was accessed, the incision was extended longitudinally to allow passage of the endoscope. $\mathbf{f}$ Having accessed the submucosal area, the submucosal tunnel could be safely opened. 


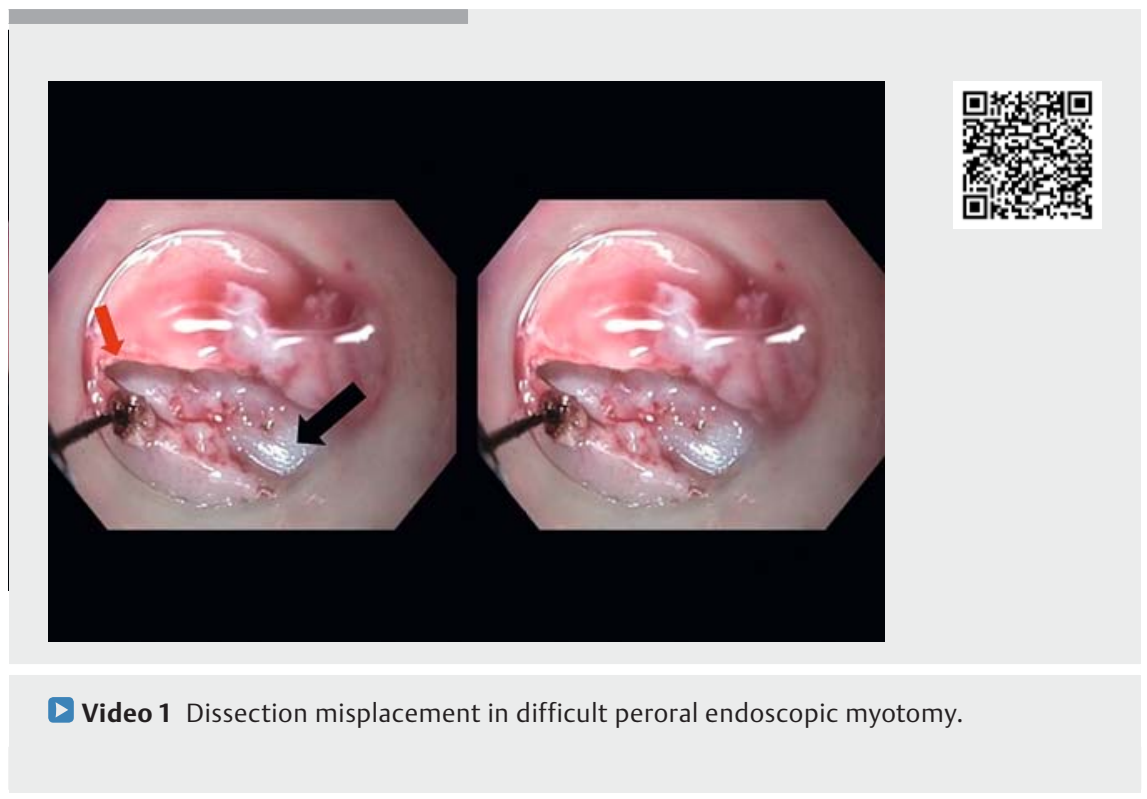

\section{Acknowledgments}

We would like to acknowledge www.makaletercume.com for their outstanding scientific proofreading and editing services that were provided for this manuscript.

\section{Competing interests}

The authors declare that they have no conflicts of interest.

\section{The authors}

\section{Süleyman Günay, Elif SarıtaşYüksel, Firdevs} Topal, Betül Paköz, Cem Çekiç, Hakan Çamyar, Sezgin Vatansever

Department of Gastroenterology, Katip Çelebi University, Atatürk Training and Research Hospital, İzmir, Turkey

\section{Corresponding author}

\section{Süleyman Günay}

Department of Gastroenterology, Katip

Çelebi University, Atatürk Training and

Research Hospital, 35360, Basınsitesi, İzmir, Turkey

Fax: +90-232-3345

suleyman.gunay@gmail.com

\section{References}

[1] Tan Y, Li C, Yan J et al. Difficult peroral endoscopic myotomy: definition and management strategies. Expert Rev Gastroenterol Hepatol 2019; 13: 933-942

[2] Feng X, Linghu E, Chai $\mathrm{N}$ et al. New endoscopic classification of esophageal mucosa in achalasia: a predictor for submucosal fibrosis. Saudi J Gastroenterol 2018; 24: $122-$ 128
[3] Zhang WG, Linghu EQ, Chai NL et al. Ling classification describes endoscopic progressive process of achalasia and successful peroral endoscopy myotomy prevents endoscopic progression of achalasia. World J Gastroenterol 2017; 23: 3309-3314

\section{Bibliography}

Endoscopy 2021; 53: E122-E123

DOI 10.1055/a-1216-0448

ISSN 0013-726X

published online 24.7.2020

(C) 2020. Thieme. All rights reserved.

Georg Thieme Verlag KG, Rüdigerstraße 14,

70469 Stuttgart, Germany

\section{ENDOSCOPY E-VIDEOS}

https://eref.thieme.de/e-videos

Endoscopy E-Videos is a free access online section, reporting 自: on interesting cases and new techniques in gastroenterological endoscopy. All papers include a high quality video and all contributions are freely accessible online.

This section has its own submission website at

https://mc.manuscriptcentral.com/e-videos 